\title{
LAS PALABRAS Y EL MUNDO. LAS REFLEXIONES ETIMOLÓGICAS DE ALFONSO DE CARTAGENA*
}

\author{
Joaquín Rubio Tovar \\ Universidad de Alcalá \\ joaquin.rubio@uah.es \\ «La palabra tiempo rompió su propia cáscara, derramó sus riquezas» \\ Virginia Woolf, Mrs. Dalloway \\ «Sì come è scritto: Nomina sunt consequentia rerum» \\ Dante, Vita nuova \\ Para Ramón Rodríguez García
}

\section{Presentación y objetivos}

La obra de Alfonso de Cartagena muestra un abanico de intereses relacionados con la filosofía (en particular la ética), la historia y el derecho. Esta variedad suele venir acompañada del afán por precisar el significado de numerosas palabras. Para Cartagena resultaba esencial utilizarlas con propiedad, y que recogiesen de manera fiel la idea que las fundamentaba para evitar errores de interpretación. Este interés le movió a buscar su contenido verdadero que, a veces, estaba escondido en su étimo. De acuerdo con la orientación didáctica de la mayoría de sus obras y con la metodología del escolasticismo, Cartagena definió conceptos, los ordenó, señaló la relación de dependencia de unos con otros, y clasificó y jerarquizó categorías. Le movía el interés por la claridad y fue un defensor de la traducción ad sensum, porque facilitaba una comprensión precisa de lo que las palabras significaban y, por tanto, de las ideas que expresaban. En varios lugares señaló que al traducir se preocupaba más del sentido que del significado concreto de los términos:

* Este estudio se inscribe en el marco del Proyecto I+D+i del MINECO: DHuMAR: Humanidades Digitales, Edad Media y Renacimiento. 1. Poesía 2. Traducción (FFI2013-44286-P), de la Universidad de Alcalá, y se publica en colaboración con el proyecto de investigación Alfonso de Cartagena. Obras Completas FFI 2014-55902-P y FFI 2017-84858-P (MINECO y MICINN, Gobierno de España). 
«más curando del seso que de la estrecha significación de las palabras» ${ }^{1}$. Su trabajo de traductor le llevó a plantearse cuestiones léxicas y otras que hoy llamaríamos hermenéuticas.

Voy a presentar ejemplos de varias de sus obras, que me servirán para explicar el valor de la etimología en su estrategia discursiva. No se trata, desde luego, de un recorrido exhaustivo, sino de una selección de casos que convienen a mi exposición. No me interesa si el resultado de sus indagaciones fue correcto o no, sino el alcance, el sentido de su investigación sobre el origen de las palabras. Adentrarse en las etimologías era para Cartagena un procedimiento destinado a conocer el significado de muchos vocablos, pero también para adentrarse en la realidad, en el significado del mundo 2 .

Me detendré también en la clase de trabajo que supone la reflexión etimológica y que relaciona el quehacer intelectual de Cartagena con los orígenes de la cultura occidental hasta llegar a pensadores de nuestros días. Considerar el origen de una palabra ha sido para muchos filósofos un estímulo para su quehacer intelectual. Cicerón ofrece a lo largo de su obra buenas muestras de cómo la indagación en la etimología estimula el pensar pues, según indica, es posible desarrollar un argumento a partir del significado de una palabra.

\section{El interés por la etimología}

El interés que muestra Cartagena por la etimología va mucho más allá del afán erudito. La referencia al origen latino o griego de una palabra aparece varias veces en sus obras: «E desta costumbre e doctrina sse crian e se producen en el omne las virtudes que llamamos morales, e el vocablo asas la muestra, ca mos quiere decir costunbre e asi moral quiere decir costunbrar». O bien: «Ca la devoçion se dize de mover que es mucho darse a alguna cosa. Por ende devotos se dizen aquellos que se dan mucho a Dios e totalmente se someten a El» $»^{3}$.

Pero no es esta clase de trabajo filológico la que me interesa ahora. Cartagena sostenía que el buen o mal uso de las palabras, el dejarse llevar por un significado equivocado, podía tener consecuencias graves tanto en el trabajo

\footnotetext{
${ }^{1}$ Alfonso de Cartagena, Libros de Tulio: De senetute, De los ofiçios, ed. y pról. de María Morrás, Alcalá de Henares, Universidad de Alcalá de Henares, 1996, p. 157. Agradezco a Ricardo Pichel Gotérrez la ayuda que me ha prestado para preparar y mejorar este ensayo.

${ }^{2}$ La etimología es una forma de pensamiento que ha condicionado el desarrollo de una parte de la cultura occidental, de ahí que sea impreciso decir que la bibliografía sobre la materia es muy abundante. Hablamos de verdaderos continentes. En estas páginas cito solamente aquellos libros y ensayos que convienen a mi exposición.

${ }^{3}$ Alfonso de Cartagena, El Oracional (comparación del Manuscrito 160 de Santander y el Incunable de Murcia), ed. crítica de Silvia González-Quevedo Alonso, Valencia-Chapel Hill, Albatros edicionesHispanofila, 1983, pp. 95 y 107.
} 
intelectual como en el comportamiento de las personas, y señalaba que la mente debía ceñirse a palabras verdaderas: «Debemos insistir con no poco esfuerzo para que nuestras palabras sean acordes a nuestros hechos», pues «quien desea seguir por completo la verdad, ¡que adapte sus actos a las palabras y sus recursos a las circunstancias!, pues a veces no mancillamos la pura verdad menos con hechos que con palabras» ${ }^{4}$.

El significado de los vocablos es mucho más que una cuestión léxica, porque su buen uso evita conducirnos a errores que trascienden los textos: «La oscuridad y la confusión, dice Cartagena, provocan equivocaciones, puesto que en nuestro común fablar todo lo mezclamos» ${ }^{5}$. El asunto es particularmente grave cuando se han de tratar aspectos éticos y científicos ${ }^{6}$. No es infrecuente que se tomen conceptos prestados de distintos campos del conocimiento, lo que trae consigo errores y equivocaciones. Cartagena alude a la proprietas de los vocablos. Me gustaría detenerme en este concepto, que el autor menciona a menudo. En más de una ocasión insiste en que es necesario conocer el sentido exacto de las palabras, su contenido auténtico (verborum proprietas) ante su volubilidad, su inestabilidad (verborum volubilitas). Y cabe recordar también que las palabras tienen varios significados, varias acepciones o sentidos. En el Oracional escribía: «Que en diversos logares de la Sagrada Escriptura fallará esta palabra adorar ha diversos respectos. Ca dízese a las veces adorar a las vezes a Dios e a las vezes a criaturas» ${ }^{7}$.

La primera pregunta que planteaba Fernando Pérez de Guzmán a Cartagena en el Duodenarium era «si el título de emperador y el de rey son idénticos o uno aventaja al otro según el valor intrínseco del término ("ex ipsa verbi

\footnotetext{
${ }^{4}$ Alfonso de Cartagena, El Duodenarium. Cultura castellana y letras latinas en un proyecto inconcluso, estudio, ed. y trad. de Luis Fernández Gallardo y Teresa Jiménez Calvente, Córdoba, Almuzara, 2015, p. 219.

5 «E aunque en nuestro común fablar todo lo mezclamos en uno e nunca o pocas vezes vistes fazer diferencia entre estos dos vocablos fazer e haz[e]r. Pero la estrecha significación dellos grand diferencia trahe e conviene que mire en ella qualquier que quisiere conosçer distintamente e sin error la existencia de las virtudes», Alfonso de Cartagena, El Oracional, ed. cit., p. 65. Se trata, para él, de desacostumbrar las palabras de su uso cotidiano.

${ }^{6}$ «Donde disputaçión de sçiençia ay es peligroso canbiar los vocablos por quanto la mudança que paresçe ser pequeña en las palabras trae grant mudamiento en el cognosçimiento del fecho», escribía Cartagena en el prólogo al segundo libro de De la clemencia. Cito por la edición de Juan Miguel Valero Moreno (en prensa), que el autor me ha permitido manejar. Agradezco su generosidad.

${ }^{7}$ Alfonso de Cartagena, El Oracional, ob. cit., p. 198. Mena escribía en el Comentario a la Coronación del Marqués de Santillana, tras la copla LI: «Muchos perdones inploro: implorar es suplicando demandar, e muchas palabras ay que paresçen tener esta significación aunque han variables respectos, ca tenemos pedir e demandar, suplicar e implorar; esta palabra demandar propiamente sirve quando omne demanda lo que suyo non es a fin de lo fazer suyo y esto a otro igual [...]; pedir, esta palabra sirve propiamente quando omne pide lo suyo a quien gelo tiene ocupado [...]», Juan de Mena, Obras Completas, ed., intr. y notas de Miguel Ángel Pérez Priego, Barcelona, Planeta, 1989, p. 208.
} 
proprietate precedat") $\rangle^{8}$. No era una pregunta cualquiera. Conviene recordar que la diferencia entre rey y emperador no fue una cuestión menor a lo largo de la Edad Media. Al final del capítulo 21 de la Quinta parte de la General estoria leemos que conviene explicar las razones por las que un emperador recibe cuatro nombres: «Octaviano, César, Augusto e emperador» ${ }^{9}$. Tras esta digresión, que ocupa el capítulo 22, leemos: «Agora diremos d'esta palabra emperador». El capítulo 23 está consagrado por completo a presentar la etimología de emperador e imperio y la de monarquía (véase el anexo). Las figuras del rey y del emperador son capitales desde la alta Edad Media y no es posible resumir aquí su trascendencia, que alcanzaba también a la teología. Cristo es llamado rex e imperator, y puede hablarse de una realeza cristocéntrica, tal y como ha demostrado Kantorowicz en una monografía imprescindible ${ }^{10}$. La reflexión sobre las palabras rey y emperador tampoco era una cuestión menor para un jurista como él. Pero vayamos a la respuesta de Cartagena, porque un fragmento de la misma nos sirve para plantear cuestiones esenciales y donde aparecerá la palabra proprietas.

\section{La propiedad de las palabras}

La pregunta a la que me refería se formulaba en los términos que siguen: «Utrum imperatoris et regis sit idem titulus vel alter alterum ex ipsa verbi proprietate precedat» ( «Si el título de emperador y de rey son idénticos o uno aventaja al otro según el valor intrínseco del término»). En las primeras líneas de la respuesta presentaba Cartagena algunas ideas que considero fundamentales:

emperadores y reyes muestran a partir del propio significado del término de dónde han tomado su nombre. Así, unos reciben su nombre de 'imperare' (imperar) y los otros de 'regere' (regir). Sin duda esta voz, en una acepción simple y general, y digerida, por asi decirlo, en el estómago, denota que a los reyes les corresponde una excelencia en su consideración por delante de los emperadores. Pues 'imperar' no es otra cosa que 'dar órdenes', ya que esta

\footnotetext{
${ }^{8}$ Alfonso de Cartagena, Duodenarium, ed. cit., p. 176.

${ }^{9}$ «El nombre de César partió de Julio César pero los nombres de "emperador" y de "Augusto" partieron de Octaviano», Alfonso X, General estoria. Quinta y Sexta partes, tomo II, ed. de Pedro SánchezPrieto y Belén Almeida, Madrid, Fundación José Antonio de Castro, Biblioteca Castro, 2009.

${ }^{10}$ Ernst H. Kantorowicz, Los dos cuerpos del rey, Madrid, Alianza Universidad, 1985. Todavía en los Comentarios reales el Inca Garcilaso recordaba los valores de rey y señor: «Y principiando del nombre Inca, es de saber que en la persona real significa rey o emperador; y en los de su linaje, quiere decir hombre de la sangre real. [...] Llamaban a sus reyes Capa Inca, que es solo rey, o solo emperador, o solo señor, y este nombre no lo daban a otro alguno de la parentela, ni aun al príncipe heredero, hasta que había heredado; porque siendo el rey solo, no podían dar su apellido a otro, que fuera ya hacer muchos reyes», ed. Enrique Pupo-Walker, Madrid, Cátedra, 1996, pp. 147-148.
} 
palabra tiene el valor general de 'orden', tanto justa como injusta, ya que se dice que impera, preceptúa u ordena tanto el que da malas órdenes como el que las da justas y, a partir de la propia naturaleza del vocablo, no se extrae ni virtud ni malicia, sino que, al compartir el doble valor de expresar el buen o mal imperio, precisa de algún calificativo; [...] Pero 'regir' no es así: por su propio sonido muestra que se trata de un 'regimiento' virtuoso, porque no parece 'regir' el que no rige bien, toda vez que regir es dirigir todas las cosas hacia una recta regla. ¿Cómo, pues, la perversión de las cosas va a ser congruente con el nombre 'regir'? [...] Todos saben que estas palabras designan el grado supremo de los gobiernos de los príncipes. Así que, según creo, quieres preguntar si estos dos nombres designan un mismo tipo de gobierno de príncipes o si uno aventaja al otro en función del propio brillo del término ${ }^{11}$.

En el título de la pregunta, queda claro que hay que acudir al significado profundo de la palabra para dilucidar conceptos y conocer su sentido y alcance. Expresiones como ex ipsa verbi significationi, ex ipsa verbi proprietate precedato o de sui natura vocabuli virtutem van en esta dirección. Y llamo la atención sobre Animadverte: imperatores et reges unde nomen sumpsserunt, donde se apela al poder inmenso del nombre, nomen, sobre el que reflexionaremos más adelante.

No es la única ocasión en la que nombra la propiedad de la palabra. En la polémica que sostuvo con Leonardo Bruni con motivo de su traducción de la Ética a Nicómaco, escribía:

Pero habida cuenta de que hemos de tratar, como anunciamos, sobre la norma no de la elocuencia, sino de la ciencia en este punto, para no confundirnos sobre las cosas mismas engañados por la falta de precisión de las palabras, no se ha de manifestar tan precipitadamente, sino que debemos extraer a partir de la propiedad misma de ellas cuál es la verdad de su contenido ${ }^{12}$.

${ }^{11}$ El texto latino dice: «Tu uero an recte dicam animaduerte: imperatores et reges vnde nomen sumpsserunt, ex ipsa verbi significatione demonstrant. Alii enim ab imperando, alii a regendo dicuntur. Que quidem uox sic nude et generaliter sumpta ac inter stomacum aliqualiter uolutata regibus profecto ultra imperatores quandam racionis excellenciam congruere denotat. "Imperare" namque nil aliud quam "precipere" est, quod vtique uerbum tam equo precepto quam iniquo habetur comune, cum imperare seu precipere aut iubere dicatur qui peruerse sicul qui iustissime iubet nec de sui natura uocabuli uirtutem aut maliciam dicit, set vtrique comunicans ut malum uel bonum imperium exprimat adieccione aliqua eget. Oportet enim ut "bene uel male imperare" dicamus, si uolumus imperandi qualitatem edicere. "Regere" uero non sic, set ex ipso dictionum strepitu régimen virtuosum demonstrat, quia non videtur regere qui non bene regit, cum regere sit res ipsas ad regulam rectam adducere; quomodo enim regendi nomini congruet ipsa perversio rerum? [...] Omnibus autem iam notum existit uerba hec principatuum excellenciam demonstrare. Illud ergo, ut reor, inquirere vis an idem principatus hiis nominibus designetur an vero alter alteri ex ipsa nominis claritate precellit», Alfonso de Cartagena, Duodenarium, ed. cit., pp. 176-177.

12 «Sed quoniam, ut praemisimus, non eloquentiae, sed scientiae morem in hoc genere debemus, ne 
Junto a proprietas encontraremos proprie y propriisime que Cartagena utilizaba también a menudo, por ejemplo en la controversia con Bruni, donde escribe: «Propriisime ergo assumptis uocabulis» («si se toman las palabras en sentido estricto») $)^{13}$.

La idea de propiedad de las palabras no aparece solamente en textos latinos, sino también en textos en castellano, donde encontramos los mismos campos semánticos. No voy a convertir este ensayo en una serie de citas encadenadas, pero quiero destacar algunos pasajes para apoyar mi razonamiento. Veamos algunos ejemplos del uso de propio, propiedad o propiamente:

La disposiçión e hábito del entendimiento que en estas dos cosas tiene grand excelençia es la virtud intelectual que se llama sapiençia que deximos sabiduria. Por ende propiamente fablando el que estas virtudes intelectuales tiene se llama sabio $^{14}$.

Al comentar el Padre Nuestro se refiere al término adveniat y al modo en que debe traducirse:

E eso bien paresçe por la propriedat del vocablo quien bien lo quisiere mirar. $\mathrm{Ca}$ non dize veniat que quiere decir venga mas adveniat que propiamente tomado quiere decir venga a nos o venga acá, porque aquella sílava -ad-que se añade faze e quiera decir venga a nos $[\ldots]^{15}$.

\section{Y en el capítulo XV escribe:}

Para conosçer [bien] la propiedad dello por quanto por muchas cosas se dize, un vocablo non se conosçe asi tan claramente la diferencia dél como quando cada cosa tiene un vocablo apartada por sy. Por ende quando fazer sse puede es provechoso dar vocablos a cada cosa por que mejor sse conosca que es de lo que omne fabla ${ }^{16}$.

uerborum uolubilitate decepti ipsis in rebus aberremus, non sic confestim praetendendum est, sed quia rei ueritas habeat ex ipsa uerborum proprietate excerpamus», Tomás González Rolán, Antonio Moreno Hernández y Pilar Saquero Suárez-Somonte (eds.), Humanismo y teoría de la traducción de España e Italia en la primera mitad del siglo XV. Estudio y edición de la Controversia Alphonsiana (Alfonso de Cartagena vs. L. Bruni y P. Candido Decembrio), Madrid, Ediciones Clásicas, 2002, pp. 254 y 255.

${ }^{13} \mathrm{Ibídem}$, p. 260, y también «Quae omnia manifeste demostarnt uoluptatis uerbum, proprie sumptum», ibidem, p. 248.

${ }^{14} \mathrm{Al}$ hablar de «las dos cosas» se refiere a los primeros principios y a las conclusiones que se extraen de ellos (Alfonso de Cartagena, El Oracional, ed. cit., p. 69).

${ }^{15}$ Ibídem, p. 128.

${ }^{16}$ Ibidem, p. 90. 
Junto al conocimiento de la propiedad de la palabra, encontraremos estrechamente:

La reverençia que se faze por los siervos a los señores se llama propiamente dulia que es una espeçie de observançia e es vocablo griego que quiere decir servidumbre. Es asy estrechamente tomada, dízesse de menor a mayor por razón de la excelencia e muéstrase bien esto por la manera del fablar comúnmente guardada en Castilla. [...] Pero estrechamente tomado el vocablo non sería propio fablar ${ }^{17}$.

Otros términos expresan la misma intención: buscar el significado exacto de las palabras. En la controversia que sostuvo con Bruni leemos:

Mas si alguna vez nos servimos de la palabra 'uoluptatis' ['placer'] en relación a aspectos espirituales o bien de la palabra 'gaudio' ['alborozo'] en cuestiones meramente corporales, lo hacemos en discursos prestados de un campo a otro; pues no nos ceñimos a la significación estricta de las palabras, hasta el punto de que sea una profanación decir alguna vez una palabra en lugar de otra. No obstante, al indagar con extremada atención el contenido mismo, entonces debemos atenernos a la propiedad estricta de las palabras ${ }^{18}$.

Proprietas, estrecha significación, strictam significationem: son expresiones que apuntan en la misma dirección. Estos términos se usaban a menudo en la época de Cartagena. La palabra propiedad está muy documentada en la lengua española. Enrique de Villena escribía en la Exposición del Salmo Quoniam videbo en 1424: «Pero si se entiende segúnt la propiedat del nombre primitivo ${ }^{19}$. Y también se refería a la propiedad del vocablo Juan Rodríguez del Padrón en el Bursario (1425-1450): «Segund la propiedat del vocablo, bursario es derivado o ha nacimiento de bursa, vocablo latino que

\footnotetext{
${ }^{17}$ Ibídem, pp. 88 y 89. Y lo mismo en la traducción de De la clemencia de Séneca: «Por ende, aunque en nuestro común fablar por la clemençia digamos piadat, o misericordia, pero aquí non lo trasladamos así, porque segunt la estrecha et propia significaçión de las palabras ay entre ellas grand diferençia. Ca una cosa es la clemençia et otra la misericordia et otra la piedat. Et non se trocará bien una palabra por otra nin creo que se fallaría en nuestro lenguaje una palabra que tomada sola la propiedat verdadera de la clemençia signifique», Juan Miguel Valero Moreno, ed. en prensa.

${ }^{18}$ «Quod si interdum uoluptatis in spiritualibus aut gaudii uocabulo in mere corporalibus utimur, hoc mutatis ab inuicem sermonibus usurpamus; nec enim adeo strictam significationem verborum attendimus, ut aliud pro alio strictam interdum dicere sacrificium sit. Sed cum materian ipsam attenta mente perquirimus, tunc ad strictam proprietatem uerborum recurramus», Tomás González Rolán et al., Humanismo y teoría de la traducción, ob. cit., pp. 252-253.

${ }^{19}$ Enrique de Villena, Exposición del salmo "Quoniam videbo", en Obras completas, vol. 1, ed. de Pedro Cátedra, Madrid, Fundación José Antonio Castro, Turner, 1994, p. 307.
} 
quiere decir en nuestro romançe bolsa ${ }^{20}$. En la quinta acepción del Diccionario de Autoridades (1737) leemos que Propiedad se toma: «Por la debida proporción, naturalidad o perfeccion con que se usa de alguna cosa o se habla de ella, sin quitar ni añadir circunstancia, que la altere u desluzca», es decir, significado o sentido peculiar y exacto de las voces o frases, como leemos en la edición actual del DRAE.

No quiero terminar este apartado sin recordar una excepción que me parece relevante. Hay una tarea intelectual en la que la proprietas no siempre es un valor esencial. He señalado al principio de estas líneas que Cartagena fue un defensor de la traducción según el sentido. En la introducción a su traslado del libro de la Rethórica escribió: «En la traslaçión del qual non dubdo que fallaredes algunas palabras mudadas de su propia significación e algunas añadidas [...] Guardada quanto guardar se puede la intençión, aunque la propriedat de las palabras se mude, non me paresce cosa inconveniente» ${ }^{21}$. Parece como si el ejercicio de la traducción ofreciera unas posibilidades (quizá licencias) que no permite otra clase de discursos. Planteo solamente esta cuestión y espero desarrollarla en otro ensayo, pues he reflexionado sobre este texto y otros semejantes, todos de autores del siglo xv.

\section{Etimologizar e interpretar}

Pero tanto si atendemos al sentido de la frase como a la traducción de «lo que la simple letra significa», es indiscutible que el interés por la correcta traducción no era cuestión menor, sobre todo cuando afectaba a palabras que encerraban un contenido moral:

En filosofía no se pueden dejar libres y sin sujeción las palabras, porque un error debido a la falta de propiedad de estas se acrecienta poco a poco hasta alcanzar a las cosas mismas ${ }^{22}$.

${ }^{20}$ Bursario, Tomás González-Rolán y Pilar Saquero (eds.), Madrid, Universidad Complutense, 1984, p. 141. Puedo aducir ejemplos de Álvaro de Luna en el Libro de las claras e virtuosas mujeres o de Diego de Valera en el Ceremonial de príncipes.

${ }^{21}$ Alfonso de Cartagena, La Rethorica de M. Tullio Ciceron, ed. Rosalba Mascagna, Napoli, Liguori, 1969 , p. 31.

22 «Nec enim in philosophia uerba sine freno laxanda sunt, cum ex improprietate uerborum error ad ipsas res paulatim acrescat», Tomás González Rolán et al., Humanismo y teoría de la traducción, ob. cit., pp. 214 y 215 . Respecto de las cosas mismas, debe recordarse la importancia de su sentido en los llamados textos enciclopédicos. El término enciclopedia aparece en el léxico intelectual europeo en el siglo XVI. Aunque no lo encontremos en la Edad Media, existió una idea muy próxima a la de enciclopedia, referida, en particular, a un libro, a una obra concreta. Algunos investigadores han destacado la importancia del cambio de título que sufren las enciclopedias en el tránsito de la Alta Edad Media a la Baja. Dejaron de llamarse etymologiae frente al preferido de natura rerum, dejaron de llamarse origines frente a De proprietate rerum, como señala Picone: «A titoli dunque che delimitano un programa enciclopédico 
No es fácil acceder a este significado propio de las palabras y la etimología es uno de los caminos para hallarla. En el Oracional escribía Cartagena:

E este vocablo se tomó de la propiedat de la palabra ethimologizando e interpretándola en una de tres maneras. La primera es deziendo religión de releer, como sy dixiesemos lección o rrelecçión. Ca quando muchas vezes leemos la Escriptura podemos decir que la releemos [...] La segunda interpretación e declaración es que sse diga religión con relecçión que es rrecogimiento. E esto, se dize segund Agustino lo tañe, porque perdimos a Dios pecando por nuestra negligencia que le tornemos a reconosçer e reescojamos con grand diligençia. [...] La tercera interpetaçión que digamos religión commo si dixiesemos rreligaçión que quier decir rreatamiento. Ca ligar es atar e rreligar es reatar ${ }^{23}$.

Etimologizando e interpretando: Cartagena une los dos gerundios mediante la conjunción. Busca la etimología para interpretar, para traducir correctamente la palabra. Utiliza los mismos vocablos unidos Juan de Mena en el comentario a la Coronación del Marqués de Santillana:

Vistas estas cosas, veamos los nombres destas sçiençias nueve de dónde los traxieron por interpretación e por etimología [...] Calíope: este nombre Calíope es dicho a calon, que dize el griego por bueno, e fonos, que dize el griego por sonido, así que Calíope quiere decir buen sonido $[\ldots]^{24}$.

\footnotetext{
definibile come grammaticale e linguistico (etymologiae o origines) si oppongono titoli che ritagliano invece un progetto enciclopédico che non si orienta più verso le parole ma verso le cose, che è insomma sperimentale e scientifico (de natura o de proprietabus rerum)», Michelangelo Picone, «Il significato di un convegno sull' enciclopedismo medievale», en L'enciclopedismo medievale. Atti del Convegno L'enciclopedismo medievale, Ravenna, Longo editore, 1994, pp. 15-21 (cita en pp. 16-17). Se pasa, como dicen García Domingo y Domínguez García, «de las palabras a las cosas mismas», lo que indica la influencia de la filosofía natural de sello aristotélico entre los estudiosos. Cosa (res), aparece en el título de varias enciclopedias escritas en este siglo (Luis García Domingo y Avelino Domínguez García, «Gil de Zamora y su Historia Naturalis: algunos aspectos del enciclopedismo en el siglo XVIII», en Estudios humanisticos. Filología, 16 (1994), pp. 115-134).

${ }^{23}$ Alfonso de Cartagena, El Oracional, ed. cit., p. 83.

${ }^{24}$ Juan de Mena, Obras Completas, ed., intr. y notas de Miguel Ángel Pérez Priego, Barcelona, Planeta, 1989, pp. 194-195. La abundancia de glosas y etimologías fue censurada una y otra vez por los humanistas. Cristóbal de Villalón criticaba los excesos de los glosadores de los cuatro libros de las Sentencias de Pedro Lombardo, uno de los compendios teológicos más reconocidos y citados desde su aparición, y señalaba que en vano encontraríamos un «punto de pura teología», ya que hallaríamos todo «contaminado y adulterado de estrañas sciencias», pues «en una questión común vienen los escriptores a desmenuçar los vocablos trayendo sus etimologías y derivaciones de la gramática, y después tratan dellos como lógicos, y después aplícanlos como philósophos», Cristóbal de Villalón, El scholástico, ed. de José Miguel Martínez Torrón, Barcelona, Crítica, 1997, Libro III, cap. X, p. 229.
} 
Los dos términos, etimologizar e interpretar, unidos por la copulativa, no son extraños en tratados eruditos $\mathrm{y}$, sin ir más lejos, los encontraremos en el Catholicón, el extenso repertorio latino. En Cadira de honor (c. 1438) de Juan Rodríguez del Padrón, el autor se refiere a la palabra nobleza y señala: «Bolviendo, segund Isidro en el nono libro de las Ethimologías, digo que desta planta nobleza, por etimología, la verdadera raíz es 'non vileza'; e noble, por síncopa, segund el Catholicón, viene de 'notable' $\gg$ '. San Isidoro y el Catholicón se citan una y otra vez en los textos que vengo recordando.

Resulta obligado recordar el peso de las Etimologías en el pensamiento de Cartagena. La relación entre el significado de las palabras y el mundo, y entre el origen de los términos y su significado son dos ideas que recorren la Edad Media. En el capítulo XXIX, dedicado a la etimología, leemos:

La etimología estudia el origen de los vocablos, ya que mediante su interpretación se llega a conocer el sentido de las palabras y los nombres. [...] Su conocimiento implica a menudo una utilización necesaria en la interpretación léxica. Pues, si se sabe cuál es el origen de una palabra, más rápidamente se comprenderá su sentido. El examen de cualquier objeto es mucho más sencillo cuando su etimología nos es conocida ${ }^{26}$.

San Isidoro relaciona así el origen, con el nombre y con la cosa, y los pone en correspondencia:

La etimología unas veces se descubre por la causa; por ejemplo, reges (reyes) deriva [de regere (regir) y] de recte agere (conducir rectamente). Otras veces por el origen, como homo (hombre) que proviene de humus (tierra). En ocasiones, por los contrarios, como lutum (lodo) deriva de lavare (limpiar) [...]. Algunas hay que proceden de una derivación nominal [...] Otras del sonido [...] Las hay que de origen griego, han pasado al latín [...] Existen, en fin, otras palabras que derivan del nombre de lugares, ciudades o ríos; lo mismo que muchas se remontan a las lenguas de distintos pueblos, por lo que a duras penas puede descubrirse su origen ${ }^{27}$.

Lo que venía a decir era que el lenguaje era un signo natural de las cosas. He mencionado antes la palabra nombre, nomen, recordada por Cartagena.

\footnotetext{
${ }^{25}$ Juan Rodríguez del Padrón, Obras Completas, ed. de César Hernández Alonso, Madrid, Editora Nacional, 1982, pp. 104 y 260-261.

${ }^{26}$ San Isidoro de Sevilla, «Sobre la etimología», en Etimologías, ed. de José Oroz Reta, intr. general de Manuel C. Díaz y Díaz, Madrid, Biblioteca de Autores Cristianos, 1982, Libro I, cap. XXIX, vers. 1, pp. 321-323 y ss.

${ }^{27}$ Ibídem, Libro II, cap. XXVII, vers. 2 y ss., p. 405.
} 
Los nombres nos dan a conocer las cosas hasta el punto de que sin ellos no tendríamos acceso al conocimiento de la realidad: «Se dice nomen (nombre), que viene a ser lo mismo que notamen (medio de designación), porque con su indicación nominal nos permite conocer las cosas. Si ignoráramos el nombre, el conocimiento de las cosas desaparecería $\rangle^{28}$. Pero san Isidoro va más lejos, porque llega a decir que el lenguaje es signo de las cosas a través de la idea: «Las palabras son imágenes del pensamiento, mediante las cuales, los hombres, en su conversación, manifiestan sus ideas $»^{29}$.

Es la correspondencia palabra-origen-significación-cosa lo que posibilita el sentido del lenguaje, tal y como se demuestra en el Libro X de la obra de san Isidoro, especie de diccionario etimológico, en forma alfabética, en el cual se analizan los nombres desde varias perspectivas, por ejemplo, el origen (origo quorundam nominum), pero también por su relación con otros términos ${ }^{30}$.

\section{La esencia y el accidente}

El Oracional es un tratado que responde a las preguntas de Fernán Pérez de Guzmán acerca de la oración, de sus clases y formas. Cartagena se sirvió de la distinción aristotélica entre esencia y accidente para abordar algunas de las cuestiones planteadas. De la misma manera que la forma esencial de la cosa no puede ser más que una, puesto que el ser es uno, las formas accidentales pueden ser muchas, pues los accidentes son muchos ${ }^{31}$. Aristóteles desarrolló esta idea con toda clase de distingos en la Metafísica y en las $\mathrm{Ca}$ tegorías, entre otras obras ${ }^{32}$. La distinción mencionada fundamenta algunas de las consideraciones de Cartagena y aparece expresada con total nitidez en

${ }^{28}$ Ibídem, Libro I, cap. VII, vers. 1, p. 287. De los textos de san Isidoro se deduce que en el nombre está lo que la cosa es y que por la palabra conocemos el mundo. En ello radica la anterioridad del lenguaje sobre la realidad.

${ }^{29}$ Ibidem, Libro I, cap. IX, vers. 1, p. 293.

${ }^{30}$ Gonzalo Soto Posada, La función de la Semejanza en las Etimologías de san Isidoro de Sevilla, Medellín, 1980. La pertinencia de la distinción entre etymologia y origo, presente ya en san Isidoro, puede rastrearse en la obra de Cartagena. Véase Carmen Codoñer, Introducción al Libro X de las Etymologiae. Su lugar dentro de esta obra. Su valor como Diccionario, Logroño, Fundación Santa María de la Cogolla, 2002.

${ }^{31}$ Lo señalaba san Isidoro: «Toda cosa que es una y se formula con una sola palabra, se manifiesta con un nombre o con un verbo», Etimologías, ob. cit., Libro VII, cap. 4, vers. 5, p. 645.

${ }^{32}$ «El Ente se dice en varios sentidos, aunque en orden a una sola cosa y a cierta naturaleza única [...] Todo ente se dice en orden a un solo principio Accidente se llama lo que ciertamente se da en algo y se le puede atribuir con verdad, pero no necesariamente ni en la mayoría de los casos [...] El accidente, por tanto, se ha producido o existe, mas no en cuanto tal, sino en cuanto otro. Sustancia se dice de los cuerpos simples, tales como la tierra, el fuego, el Agua y todas las cosas semejantes [...] Y todas estas cosas se llaman sustancias porque no se predican de un sujeto, sino que las demás cosas se predican de estas. Y, en otro sentido, se llama substancia lo que sea causa inmanente del ser en todas aquellas cosas que no 
varios momentos del tratado ${ }^{33}$. Interesa plantear en qué medida afectó a su reflexión sobre el origen de las palabras y su significado.

El capítulo XXV está dedicado a responder cuál es la forma de la oración. «Dos maneras ay en forma: una forma es essençial e otra forma acçidental. La essençial es aquella que da el ser a la cosa cuya forma es, e la conforma en su ser; la forma acçidental es la que non da el ser a la cosa, mas dale la calidad de ser», y concluye que «la forma essençial de la oración es aquella que le da la exsençia e el ser» (p. 118). La base del conocimiento de las cosas implica conocer su esencia: «es de considerar que de cualquier cosa que omne quiere fablar primero debe saber [que cosa es] que suelen llamar los filósofos quedidad; que quiere decir lo que es» (p. 112). El problema mayor parece ser cómo acceder a la esencia, con qué términos expresarla, y para ello Cartagena se sirvió de los conceptos que le brindaba la filosofía: «La oraçion es aquella elevaçion que omne faze de su entendimiento en pensar en Dios en uno con la voluntad de se allegar» (p. 116). Como la consideraba un acto interior esencial del ser humano, dice que era «escudo interior con el qual el coraçón humano levanta quando puede su entendimiento». Pero no es infrecuente que acuda a símiles, «la oración es commo un declarador o mensajero que declara a Dios nuestro deseo» (p. 127) y, a veces, a ejemplos: «La missa es la más alta de las oraciones» (p. 127). También las autoridades pueden servir de guía para definir el concepto:

E para saber desta guissa que cossa es oraçión oyamos a Ysidoro que dize en sus Ethimologias que 'orar es esso mesmo que decir o fablar'. E Casiodoro dize que 'oraçión es oris raçio, que quiere decir razón de la boca'.

Tras desechar boquear e parlar, porque le parecen vulgares, señala que prefiere «orar por dezir o fablar o razonar. E commo la razón sea acto del entendimiento, asy la oraçion es acto de la humana virtud e potencia intelectiva» (p. 113). No en vano, «la oración de la que fablamos es acto de la razón» (p. 115).

Algunos términos expresan un significado esencial, y otros aportan matices y se refieren a los accidentes. De acuerdo con ello, sería posible establecer una relación de términos que expresasen conceptos esenciales y otra de palabras que solamente aportarían circunstançias o guarneçiones. A juzgar por las largas digresiones y detalladas clasificaciones, es más sencillo

se predican de un sujeto», Aristóteles, Metafisica, ed. y trad. de Valentín García Yebra, Madrid, Gredos, 1982 ( $2^{\mathrm{a}}$ ed. revisada). Las citas proceden del Libro IV, cap. 2 y Libro V, cap. 30 y cap. 8, respectivamente.

${ }^{33}$ Las páginas entre paréntesis corresponden a la edición de Silvia González-Quevedo, ya citada. 
presentar los accidentes del término, la variedad de formas. El capítulo XXVI (pp. 121-123) está dedicado por entero a la oración, que presenta formas muy variadas:

La forma açidental de la oraçion non es una sola, mas son muchas. Ca la forma essençial de la cosa non pueda ser mas de una, pues el ser non es mas de uno, pero las formas acçidentales pueden ser muchas. Pues los açidentes son muchos. Es para espremir algunas destas formas que podemos llamar çircunstançias, e como guarneçiones de la oraçión es de considerar que dos maneras ay: [de oraçión] la una es particular e privada [...] la otra es común [...] A la primera comoquier que para su puro ser basta aquel acto interior del coraçón.

Para su bienser, continúa, «son conplideras algunas cosas que serían largas de decir», de ahí que, «rrecoligiré aquí aquellas que a la péñola vinieren». Y a partir de este punto, Cartagena indica los rasgos necesarios para que una oración sea perfecta, y va estableciendo clasificaciones, las maneras o clases de petición, etc. Para el obispo de Burgos, la oración es solo una y los modos en que se expresa, los lugares en los que se realiza, las maneras, las actitudes de quien ora son variadas y no se deben confundir con la esencia de un acto tan trascendente ${ }^{34}$.

No creo que pueda deducirse de lo expuesto hasta ahora que la esencia de un concepto se exprese en su étimo. Pero sí creo que a la hora de buscar un significado exacto de la palabra, la proprietas, conocer su origen y su significado original, eran para Cartagena una ayuda inestimable. Cuando distingue entre verdad, vericidat y veraçitat señala que «La verdat es por respecto a la cosa mesma, o esto es verdad o non, por respecto a ello mesmo non por respecto alguno de quien lo dixo» (p. 99). La verdad de un concepto, la esencia, están por encima de la contingencia de las palabras, de su origen, pero la etimología no enturbia la búsqueda, sino que la facilita.

La palabra, la variedad de palabras y, sobre todo, el uso preciso de los términos, nos ayudan a entendernos: «Un vocablo non se conosçe así tan claramente la diferencia dél como quando cada cosa tiene un vocablo apartada por sy» (p. 90). Lo que no significa que deba desecharse la variedad: «la diverssidat de los vocablos faze mejor entender la diversidad de las cosas e quita las equivocaciones que suelen traer obscuridat e confusión».

${ }^{34} \mathrm{Al}$ explicar las peticiones que se incluyen en esta oración, se refiere al «fyn deseado» (p. 128) y aclara: «Las cosas que pertenesçen ordenadamente para mas ayna alcançar este fyn son de dos maneras: la primera es por sy principalmente, la segunda es acçidentalmente. Principalmente se dize aquello que ayuda para alcançar el fyn tendiendo en él derechamente. Acçidentalmente se dize aquello que ayuda para alcançar el fyn non derechamente tendiendo» (pp. 128 y 129). 


\section{La semejança del mundo}

El término semejança está cargado de sentido e intención y se cita en varias ocasiones en las Etimologías ${ }^{35}$. Los hombres, escribía san Isidoro, pusieron nombres a los ganados, a las bestias y a las aves, movidos por una relación de semejanza con determinada $\operatorname{cosa}^{36}$, a la cual se parecen y de la que surge su nombre. Los dientes caninos reciben este nombre ya que, a semejanza de los perros, ad similitudinem canorum, quiebran con ellos los huesos, parten lo que los incisivos no pueden ${ }^{37}$. El río Tigris toma su nombre de tigre, el de la carrera veloz, y no sin razón, pues es el más rápido de los ríos ${ }^{38}$. El malleolus, el nuevo sarmiento de la vida, se llama así por su semejanza con el martillo (malleolus, es decir, martillejo), maleus, ob similitudinem rei (Libro XVII, cap. V, n. 5$)^{39}$.

La semejanza posibilita y fundamenta el saber de las Etimologías. El significado de la palabra explicado con la metodología de san Isidoro «cobra sentido por su parentesco, por su comunión de propiedades con su origen $»^{40}$. Trabajaba siempre a partir de la convicción de que había una correspondencia, un parentesco entre el origen y el significado. Estamos ante un procedimiento que ha dirigido durante siglos los fundamentos del saber en Occidente, según señalaba Foucault:

Hasta fines del siglo XVI, la semejanza ha desempeñado un papel constructivo en el saber de la cultura occidental. En gran parte, fue ella la que guió la exégesis e interpretación de los textos; la que organizó el juego de los símbolos, permitió el conocimiento de las cosas visibles e invisibles, dirigió el arte de representarlas. El mundo se enrollaba sobre sí mismo: la tierra repetía el cielo, los rostros se reflejaban en las estrellas $[\ldots]^{41}$.

La palabra es la que ordena las categorías, se acude a ella para sancionar la realidad, dar carta de naturaleza al mundo y determinar cómo debe ordenarse: rey es superior a emperador, pues así lo expresan estos términos. Recuérdese

${ }^{35}$ «La homéosis es lo que el latín traduce por 'similitud': por medio de ella, una cosa menos conocida es dada a conocer gracias a la semejanza que tiene con otra más conocida», san Isidoro de Sevilla, Etimologías, ob. cit., Libro I, cap. XXXVIII, 31.

${ }^{36}$ Ibídem, Libro XII, cap. VI, 4.

${ }^{37}$ Ibidem, Libro IX, cap. I, n. 52.

${ }^{38}$ Ibidem, Libro XII, cap. II, n. 7 y Libro XIII, cap. XXI, n. 9.

${ }^{39}$ Gonzalo Soto Posada, La función de la Semejanza, ob. cit., p. 63. Hago constar la deuda que tienen estas páginas con el ensayo de este autor.

${ }^{40}$ Ibidem, p. 29.

${ }^{41}$ Michel de Foucault, Las palabras y las cosas, trad. de Elsa Cecilia, Barcelona, Siglo XXI, 1988, p. 26. 
cómo manifestaba Cartagena su sorpresa ante el hecho de que alguien dudara de la verdad de una palabra: «¿Cómo, pues, la perversión de las cosas va a ser congruente con el nombre 'regir'? [...] Todos saben que estas palabras designan el grado supremo de los gobiernos de los príncipes $\rangle^{42}$.

La relación entre la palabra y el mundo, tal y como la plantea Cartagena, se inspira en gran medida en las Etimologías de san Isidoro. Una de las conclusiones que se extrae de aquella vasta obra es que podemos conocer la realidad del mundo (medicina, leyes, religiones, geografía, agricultura, historia natural, cosmología, lenguas, razas, animales y monstruos, caminos o costumbres, etc.) gracias a las palabras y, más en concreto, gracias a su etimología, pues ella demuestra que todos los saberes están conectados.

\section{Las palabras y el mundo}

La preocupación por el significado exacto de las palabras y por su empleo preciso son hechos reveladores. El mundo no está ante nosotros para ser nombrado, pero sin la lengua no tendríamos acceso a su conocimiento o sería de muy distinta naturaleza. Tampoco serían posibles las leyes ni los códigos que jerarquizan y ordenan nuestras acciones, ni sería posible el pensamiento. Las palabras no flotan en el aire ajenas a la realidad y nos informan de lo que una sociedad considera importante. La dimensión ética y política del lenguaje, la relación del mundo con las palabras, son preocupaciones que laten en el fondo del pensamiento de Cartagena. El estudio de la polémica entre Bruni y el obispo de Burgos sobre la traducción de la Ética a Nicómaco revela que Cartagena no perdonaba errores en la traducción de conceptos que él consideraba fundamentales. La degradación y el mal uso del lenguaje eran signos de males mayores. En este punto, Cartagena es heredero lejano de preocupaciones que aparecen ya en la antigua Grecia ${ }^{43}$. Tucídides habla de los horrores que se produjeron en las ciudades durante la guerra civil y relata los extremos

\footnotetext{
${ }^{42}$ Duodenarium, ed. cit., p. 177.

${ }^{43}$ La percepción del cambio de significado en las palabras y sus consecuencias aparece ya en Platón: «Esta nuestra hermosa lengua, de hoy, dice Sócrates en el diálogo Crátilo, ha retorcido los nombres déon y zémiǒdes hasta hacerlos significar lo contrario; ha borrado lo que significan, mientras que la antigua lo muestra a las claras». Hermógenes le pide que aclare estas palabras y Sócrates da más ejemplos en los que las palabras han cambiado y continúa explicando el término himéran: «¿Y no sabes que sólo este nombre arcaico manifiesta la intención del que lo puso? En efecto, como la luz nacía de la oscuridad, con la complacencia y 'deseo' de los hombres [...]», Platón, Crátilo, en Diálogos II. Gorgias, Menéxeno, Eutidemo, Menón, Crátilo, trad. e intr. de J. Calonge Ruiz, E. Acosta Méndez, F. J. Olivieri, J. L. Calvo, Madrid, Gredos, 1983, pp. 418 y 425. Resulta muy estimulante la lectura de Francisco García Jurado, «La etimología como forma de pensamiento. Ideas lingüísticas e historia de la cultura», en Revista Española de Lingüística, 31:2 (2001), pp. 455-492.
} 
a los que se llegó. El uso perverso e inexacto del lenguaje y su apropiación por los demagogos llevaron a la implantación de la tiranía en Atenas. El significado de las palabras se modificó para justificar el sentido de los hechos:

La audacia irreflexiva fue considerada entrega valerosa al partido, y, en cambio, la calma prudente, cobardía especiosa. [...] La precipitación desconcertante fue tenida por cualidad viril, y el maquinar en pro de la seguridad por engalanado pretexto para desertar. El disconforme con todo pasaba siempre por leal, mientras el que le replicaba, por sospechoso. Si alguien conspiraba con éxito era tenido por inteligente, pero quien lo barruntaba, más listo aún. [...] En consecuencia, ni unos ni otros se regían por la piedad, sino que por la beldad de sus palabras gozaban de mayor prestigio quienes lograban sus éxitos de un modo abominable ${ }^{44}$.

Al referirse a la crisis de la República romana, el historiador Salustio presentaba a Catón el Joven identificando el mal uso del lenguaje -en concreto, la escisión entre palabra y significado- como causa subyacente a la amenaza del estado. La sociedad, dice Catón, ha perdido los vera vocabula rerum, literalmente, los verdaderos nombres de las cosas.

A primera vista, nuestro lenguaje es suficiente para decir lo que queremos decir sobre el mundo o, en otras palabras, la realidad se deja decir por nuestro lenguaje. Si la lengua cotidiana es insuficiente, entonces la etimología no aporta nada para la comprensión. Pero Cartagena no participaba de esta fe en la lengua de todos los días. Como para otros autores, la etimología era un camino para recuperar el sentido profundo de las palabras, una pista sobre experiencias perdidas y no sedimentadas en el lenguaje. Queremos saber dónde y cómo empiezan las cosas, buscamos sabiduría en las etimologías, nos gusta estar presentes en los nacimientos, tal vez porque sentimos, como escribía Alberto Manguel, «que lo que llega primero a este mundo justifica o explica lo que viene después» ${ }^{45}$.

El estudio de la relación entre el lenguaje y la realidad es antiguo y no procede ni siquiera esbozar un resumen de las propuestas que han realizado filósofos y lingüistas de todas las orientaciones posibles. Es probable que la necesidad de referirse a las cosas del mundo, de exigir la realización de algunas acciones sobre ellas, condicionara y estimulara el desarrollo del lenguaje. Lo cierto es que las palabras moldeadas por y para el uso común

\footnotetext{
${ }^{44}$ Tucídides, Historia de la Guerra del Peloponeso, ed. y trad. de Francisco Romero Cruz, Madrid, Cátedra, Letras Universales, 1988, Libro III, nº 82, pp. 289, 290 y 291.

${ }^{45}$ Alberto Manguel, Una historia natural de la curiosidad, trad. Eduardo Hojman, Madrid, Alianza, 2015, p. 64 .
} 
adquirieron el poder de moldear el pensamiento. Esta relación «según la cual las palabras nos conciben, es decir, que no solo expresan, sino que crean el pensamiento» ${ }^{46}$ está en la base del quehacer de varias escuelas filosóficas. Las palabras de otros, vengan de remotas tradiciones, de autores más que lejanos, nos ayudan a pensar. El lenguaje, escribe Heidegger, «abre el camino a todo querer reflexionar» ${ }^{47}$.

Para Heidegger, la etimología no pretende la recuperación de una palabra anticuada con fines eruditos, sino el permitir redescubrir, desocultar lo que el ser había revelado antes y se había ocultado con el paso del tiempo para mostrar algo diferente. Una de sus indagaciones en el terreno del lenguaje consistió en redefinir, a través de la etimología griega, el concepto de verdad en la filosofía. Flórez Restrepo ${ }^{48}$ señala que si Heidegger solo hubiera realizado un ejercicio etimológico del origen material de la palabra, habría seguido sosteniendo que verdad tiene su origen en el conocimiento latino de veritas, entendido como correspondencia entre el enunciado y la cosa que enuncia, pero esta idea de adcequatio desorienta la esencia de la verdad. Su trabajo con la etimología le sirvió para reorientar la unidad palabra-significado-cosa mediante un nuevo camino: des-ocultación de la verdad. Si se entiende que el lenguaje es solamente un instrumento para relacionarnos con el mundo o para nombrar la realidad, la etimología solo realiza una función esclarecedora de campos semánticos o como herramienta de la gramática comparada. El concepto de verdad, recuperado gracias a la etimología (a-letheia: desocultación, desvelamiento), permite concebir el modo de manifestación del ser. La traducción latina de los textos griegos provocó la pérdida del contenido de la lengua griega. Heidegger interpretó el poema de Parménides a través de un profundo ejercicio filosófico sobre la palabra aletheia, y sobre la historia de su traducción, el conflicto de su desocultamiento-ocultamiento, la mirada y el ser. Se trataba de habitar un lenguaje que fuese una experiencia significativa del mundo. El camino emprendido por el filósofo consistió en un ejercicio etimológico que le permitiera determinar el sentido de los términos. El único modo de llegar al ser es el lenguaje («la casa del ser»), pues es allí donde habita. El discurso heideggeriano se vuelve preferentemente etimológico, pero lejos de las preocupaciones filológicas. Son muchos los términos,

${ }^{46}$ Alberto Manguel, La ciudad de las palabras: mentiras políticas, verdades literarias, Barcelona, RBA, 2010, p. 80.

${ }^{47}$ Ramón Rodríguez García, Heidegger y la crisis de la época moderna, Madrid, Síntesis, 2006, p. 178.

${ }^{48}$ Jorge Alejandro Flórez Restrepo, «La etimología de verdad y la verdad de la etimología. El retorno de Heidegger a los orígenes del lenguaje filosófico en Grecia», en Foro de Educación, 3:5-6 (2005), pp. 110-119. 
tanto de la tradición filosófica occidental, como de su propio pensamiento, que han sufrido un análisis de su etimología. Pensemos en el uso que para la elaboración de su pensamiento ha hecho Heidegger de las palabras Lichtung y su parentesco con Licht y leicht; Ereignis y su relación literal con eignen, aneignen, vereignen, zueignen. Lo de menos es la corrección filológica y, lo de más, la inventiva y la creación de novedad ${ }^{49}$.

La preocupación de Cartagena por el uso preciso de términos capitales de la tradición filosófica y teológica, su interés por evitar malentendidos e interpretaciones equivocadas, pero, sobre todo, su interés por las palabras, por lo que él consideraba su sentido, lo convierten en un eslabón importante en la larga cadena de pensadores que se han preguntado por la relación entre las palabras, el mundo y las acciones de los hombres. En su obra se plantea, además, un problema de gran envergadura, como es la relación entre el lenguaje y la realidad, que es otra forma de designar el problema de la verdad. En nuestros días, y según ciertos discursos filosóficos, parece que la realidad se aleja y se sustituye por narraciones y lenguajes. El enorme prestigio que se ha dado al lenguaje, sobre todo tras el llamado giro lingüístico, «produce el descrédito de la realidad y la devaluación de la noción de verdad $»^{50}$. Debilitadas o reafirmadas, cargadas de significado o convertidas en balbuceo, la historia de las palabras y de su relación con la realidad sigue viva. Las cosas que ocurren, como las palabras, no terminan nunca.

Recibido: $31 / 05 / 2018$

Aceptado: 10/07/2018

${ }^{49}$ Ramón Rodríguez García, Heidegger y la crisis, ob. cit., p. 180.

${ }^{50}$ José Antonio Marina, La selva del lenguaje, Barcelona, Anagrama, 1997, p. 185. 


\section{ANEXO}

D'este nombre emperador dónde fue tomado e qué quiere dezir e a quién debe ser llamado

Dizen en el latín parare por aparejar; e esta palabra parare segunt cuenta Ugucio e otros compónese con in, e dizen imperare, e imperare en el latín quiere decir en el lenguaje de Castilla como mandar todos e señorear, e d'este imperare por tal manera viene este nombre imperator que es por emperador; e emperador por mandador, porque el emperador es señor que manda e aseñorea sobre otros e sobre reyes, e non ninguno sobre él si non Dios. E de otra manera aun semeja que este latín imperare tanto quiere mostrar como desaparejarse o non aparejar o desigualarse de otros, e quiere esto dar a entender que emperador tanto es como que non á par en los omnes nin debe aver quien sea su igual nin quien se le deva aparejar nin igualar entre los otros príncipes del su imperio. $\mathrm{E}$ aun inperare da a entender que debe estar el emperador toda vía aparejado contra los que se le enfestaren para domarlos e fazerles obedecer. E por tal príncipe dixeron los sabios en sus escriptos este nombre emperador e al señorío d'él imperio, onde ovo aquel príncipe Octaviano por las razones dichas estos tres nombres, César de su tío; Agusto porque acreció el señorío más que otro príncipe romano; e emperador porque señoreó a todo el mundo, ca pues que fue llamado emperador aquel príncipe Octaviano Céssar Agusto de estonces adelante, segund cuenta Orosio, fue la suma de todas las cosas e de los poderes del mundo ayuntada en la mano e en el governamiento del emperador Octaviano Céssar Agusto solo, e así duró en él allí adelante en toda su vida ${ }^{51}$.

En el estudio que acompaña el Lapidario y el Libro de las formas e imágenes que son en los cielos de Alfonso X, Pedro Sánchez-Prieto ha destacado el interés metalingüístico de los alfonsíes y de sus fuentes por mostrar las correspondencias entre los nombres de las piedras (y las lenguas que las expresan), y la descripción de las cualidades físicas y los usos farmacológicos. Aunque estas correspondencias puedan tener su origen en la fuente, no deben descartarse desarrollos característicos de los colaboradores regios, «dentro de una concepción onomasiológica que ve en la etimología (en el sentido medieval del término) una vía de conocimiento acerca de la realidad extralingüística $\rangle^{52}$.

\footnotetext{
${ }^{51}$ Alfonso X, General estoria. Quinta y Sexta partes, ed. cit., pp. 471-472.

${ }^{52}$ Alfonso X, Lapidario. Libro de las formas e imágenes que son en los cielos, Madrid, Fundación José Antonio de Castro, Biblioteca Castro, 2014, pp. 424-425.
} 
$\cos$

\author{
LAS PALABRAS Y EL MUNDO. \\ Las Reflexiones etimológicas de Alfonso de Cartagena
}

Resumen: El uso preciso de las palabras y la búsqueda de su significado exacto son dos ideas que fundamentaron algunas obras de Cartagena. En ocasiones indagó también en la etimología para justificar sus argumentos. La influencia de la obra de san Isidoro y del pensamiento de Aristóteles, así como sus profundos conocimientos teológicos, están en la base de muchas de sus disquisiciones.

Palabras Clave: Alfonso de Cartagena. Etimología. Traducción. Isidoro de Sevilla. Aristóteles.

THE WORDS AND THE WORLD.

The etymological reflections of Alfonso de Cartagena

ABSTRACT: The precise use of words and the search for their meaning are two ideas that laid the groundwork for some of Cartagena's works. Sometimes he also inquired into the etymology to justify his arguments. The influence of the work of Saint Isidore and the thought of Aristotle, as well as his profound theological knowledge, are at the basis of many of his disquisitions.

KeYwords: Alfonso de Cartagena. Etymology. Translation. Isidore of Seville. Aristotle. 